\title{
Development and Validation of a Method to Quantify Midazolam in a New Oral Formulation for Pediatric Use
}

\author{
Carmen Flores Pérez ${ }^{1}$, Juan Luis Chávez Pacheco ${ }^{1}$, Janett Flores Pérez ${ }^{1,2}$, \\ Hugo Juárez Olguín ${ }^{1,2^{*}}$, Blanca Ramírez Mendiola ${ }^{1}$, Raquel García Álvarez ${ }^{1}$, \\ José Francisco González Zamora ${ }^{3}$, Ángel Changin Guerra ${ }^{4}$ \\ ${ }^{1}$ Laboratorio de Farmacología, Instituto Nacional de Pediatría (INP), Mexico City, Mexico \\ ${ }^{2}$ Departamento de Farmacología, Facultad de Medicina, Universidad Nacional Autónoma de Mexico, Mexico City, Mexico \\ ${ }^{3}$ Departamento de Anestesia y Quirófano, INP, Mexico City, Mexico \\ ${ }^{4}$ Chocolates Turín ${ }^{\circledR}$, S.A. de C.V., Mexico City, Mexico \\ Email: ${ }^{*}$ juarezol@yahoo.com
}

Received June 14, 2012; revised July 18, 2012; accepted July 29, 2012

\begin{abstract}
Aim: To develop an HPLC method to quantify midazolam in a new oral formulation for pediatric use. Methods: The stability of the new formulation was evaluated at different storage conditions and a preliminary assay of relative bioavailability was carried out in healthy volunteers. Results: The method of quantification was linear in the range of 5 to $60 \mu \mathrm{g} \cdot \mathrm{mL}^{-1}$. The midazolam amount in the formulation remained stable for 90 days at 4 and $40^{\circ} \mathrm{C}$ (in the dark) while at $25^{\circ} \mathrm{C}$ was stable only for 14 days (exposed to light). Discussion: The relative bioavailability assay suggests that our preparation of midazolam in white chocolate reaches plasma levels similar to those induced by the apple juice formulation. Conclusion: This new white chocolate formulation masks the unpleasing flavour and has a more attractive presentation to the paediatric patient, which may be useful for children sedation and to ease its management by health carers.
\end{abstract}

Keywords: Children; Liquid Chromatography; Magistral Formulation; Midazolam

\section{Introduction}

Drug prescription to pediatric patients is a serious problem in several circumstances: most medicines have been assayed and approved for adult use only; also, a great variety of drugs are neither available in an adequate paediatric formulation or in an appropriate dosage forms for children $[1,2]$. In our country, drugs as captopril, furosemide, omeprazole, prednisone, midazolam and recently sildenafil, are prescribed to children, even though the pediatric pharmaceutical presentations are not available [3].

Midazolam is a drug commonly prescribed to children, and it is a short-acting benzodiazepine employed for sedation and for induction of anaesthesia, due to its sedative, amnesic and anxiolytic effects [4]. This compound is available in $7.5 \mathrm{mg}$ tablets and in 5,15 and $50 \mathrm{mg} \mathrm{mi}-$ dazolam hydrochloride injections.

In recent years in our institution, about $40 \%$ of the patients submitted to ambulatory surgical procedures were administered with midazolam orally (I.V. solution) in apple juice; however, the use of such formulation has the disadvantage of having a sour and displeasing flavour

\footnotetext{
"Corresponding author.
}

and occasionally it is rejected by some patients. Some studies shown the use of different combinations of midazolam I.V. solutions with different sweeteners such as glucose syrup, fruit juice or gelatine, to mask the displeasing flavour [5-7]; these formulations contain 0.25 $\mathrm{mg} \cdot \mathrm{Kg}^{-1}$ and up to $1 \mathrm{mg} \cdot \mathrm{Kg}^{-1}$ doses. It has been reported that $0.5 \mathrm{mg} \cdot \mathrm{Kg}^{-1}$ given orally has been the safest and more effective pre anaesthetic dose, and higher doses could induce adverse effects without offering further beneficial sedation [8].

The aims of the present work were to prepare a midazolam oral formulation using cocoa butter base (white chocolate) and to develop and validate an analytical method to quantify the drug in the formulation. The midazolam formulation was prepared to obtain a solid presentation and easy to swallow by pediatric patients; and also, safe, effective, with good taste and attractive for the paediatric population.

The analytical method to assay midazolam concentrations in white chocolate is exposed here; stability of the new formulation in different storage conditions for up to 90 days is included. A preliminary assay of relative bioavailability of the new formulation versus the administration in apple juice is described. 


\section{Material and Methods}

\subsection{Reagents}

All reagents were analytical or HPLC grade. Midazolam, acetylsalicylic acid and potassium dihydrogen phosphate were purchased from Sigma (MO, USA), acetonitrile from Caledon (Ontario, Canada) and methanol from Merck (Darmstad, Germany). Primary standards as acetaminophen, dextromethorphan, metronidazole, naproxen, propafenone, propranolol, ranitidine, sulfamethoxazole, trimethoprim and verapamil were from ICN Biomedicals Inc. (OH, USA). Captopril, ketorolac, meloxicam and piroxicam were USP grade. Midazolam hydrochloride injection Relacum ${ }^{\circledR}$ (PiSA, Mexico City) was used to perform the new formulation, for being the trademark currently used in our institution.

\subsection{Chromatographic Conditions}

A Waters HPLC system (Milford, MA, USA) consisted of autosampler (model 717), UV-detector (model 2487) and pump (model 515). Separation was performed on a column Varian Pursuit ${ }^{\mathbb{B}} \mathrm{C} 18(150 \times 3.9 \mathrm{~mm}, 5 \mu \mathrm{m})$ at room temperature. The mobile phase was an isocratic mix of $35 \mathrm{mM}$ potassium phosphate buffer $(\mathrm{pH}=4.4)$ and acetonitrile $(70: 30 \mathrm{v} / \mathrm{v})$ with flow rate of $1 \mathrm{~mL} \cdot \mathrm{min}^{-1}$; compounds were detected at $220 \mathrm{~nm}$. Data were recorded and processed using the Millennium ver 32.0 software (Waters Inc).

\subsection{Preparation of Midazolam Oral Formulation}

The formulation was prepared using a $5 \mathrm{mg} \cdot \mathrm{mL}^{-1}$ midazolam solution $\left(\right.$ Relacum $_{\circledast}$ ). We selected cocoa butter as vehicle to make the oral formulation; cocoa butter is used to prepare a candy with great approval into the Mexican pediatric population: white chocolate. This product contains at least $20 \%$ cocoa butter, about $14 \%$ of total milk solids, not less than $3.5 \%$ milk fat, and not more than $55 \%$ carbohydrate sweeteners [9]. Midazolam I.V. solution was added to prepare white chocolate bars containing $6 \mathrm{mg}$ midazolam (amount of drug given as premedication in our institution). The process of manufacturing and the recipe for this formulation is not described herein, since the patent is under arrangements. The register of the patent belongs to the National Institute of Pediatrics.

\subsection{Midazolam Extraction from Chocolate (Cocoa Butter) Matrix}

To one gram of thoroughly sliced white chocolate, $3 \mathrm{~mL}$ of methanol was added and put in a $15 \mathrm{~mL}$ centrifuge tube, then mixed by vortex $(2 \mathrm{~min})$, sonicated $(5 \mathrm{~min})$ and centrifuged at $3000 \mathrm{rpm}(10 \mathrm{~min})$. The pellet under- went a second extraction procedure, by adding $3 \mathrm{~mL}$ of methanol and performing the steps as described. The final volume $(\sim 6 \mathrm{~mL})$ was adjusted to $5 \mathrm{~mL}$ by evaporating it under controlled air stream. $200 \mu \mathrm{L}$ of methanolic solution were mixed with $50 \mu \mathrm{L}$ of external standard and then $50 \mu \mathrm{L}$ were injected into the HPLC system.

\subsection{Validation Procedures}

This work is based on the Mexican Official Guidelines to perform the stability of drugs [10], and on the bioequivalence guidelines [11]. The method of midazolam quantification in white chocolate was validated according to the guidelines [11]. Calibration curves were constructed by plotting the peak-area ratios of drug to that of the standard against known concentrations; data were fitted by linear regression analysis. The curve concentration points of midazolam were $5,10,20,30,40$ and $60 \mu \mathrm{g} \cdot \mathrm{mL}^{-1}$. Propranolol $\left(100 \mu \mathrm{g} \cdot \mathrm{mL}^{-1}\right)$ was added as external standard. $200 \mu \mathrm{L}$ of each curve solution were mixed with 50 $\mu \mathrm{L}$ of standard, and then $50 \mu \mathrm{L}$ were injected to the system.

For the intra-day accuracy, three control concentrations $\left(15,25\right.$ and $\left.50 \mu \mathrm{g} \cdot \mathrm{mL}^{-1}\right)$ were analyzed by quintuplicate; to perform the inter-day variability the same concentrations were analyzed by triplicate for three consecutive days. Values with coefficient of variation (CV) lower than $15 \%$ were accepted.

Absolute recovery was determined as the percentage of drug obtained by methanol extraction compared to the drug dissolved in methanol (analysis by triplicate). The limit of detection (LOD) was considered as the smallest amount that could be reliably discernible from the background noise (ratio signal/noise $\geq 3.0$ ), whereas the limit of quantification (LOQ) was considered as the lowest concentration in the calibration curve injected and analyzed in five independent sets, only if the mean value is in the range of $\pm 20 \%$ of the nominal concentration and its CV was lower than $20 \%$.

The long-term stability of midazolam into chocolate bar was assayed at different conditions: at room temperature $\left(25^{\circ} \mathrm{C}\right)$ without light protection, and also in darkness at $4^{\circ} \mathrm{C}$ (in refrigerator) and at $40^{\circ} \mathrm{C}$ (in oven). The amount of midazolam in samples stored at $25^{\circ} \mathrm{C}$ was quantified at 0,6 and 24 hours and also for $7,14,30,60$ and 90 days, the samples stored at 4 and $40^{\circ} \mathrm{C}$ were analyzed at $0,3,7,14,30,60$ and 90 days.

Stability of extracted samples and then stored at $-20^{\circ} \mathrm{C}$ for 24 and 48 hours was assayed, the effect of three freeze-thaw cycles was determined; these assays were performed with $1 \mathrm{~g}$ of white chocolate bars containing the midazolam control concentrations.

Selectivity was assessed with drugs that can be administered concomitantly to pediatric patients: acetamino- 
phen, acetylsalicylic acid, captopril, ketorolac, metronidazole, nimesulide, ranitidine, sulfametoxazole and trimethoprim. All were prepared at $100 \mu \mathrm{g} \cdot \mathrm{mL}^{-1}$.

\subsection{Bioavailability Assay}

A preliminary assay was carried out to compare the relative bioavailability of midazolam in white chocolate versus in apple juice. Two healthy adults (33 years old and $68 \mathrm{Kg}$ mean weight), were included in a crossed assay, which was conducted in accordance to ethical guidelines. None medication was administered to the volunteers for at least one week before and during the study.

For the assay, volunteers were catheterised at 7 a.m., blood samples $(5 \mathrm{~mL})$ were obtained at $0,0.5,1,1.5,2,4$ and 6 hours after drug administration. In first phase, single oral 6-mg doses of midazolam $\left(\right.$ Relacum $\left.^{\mathbb{B}}\right)$ in apple juice (10 mL final volume) were administered. In each sampling time, heart rate (HR) and blood pressure were recorded, and then, the mean arterial pressure (MAP) was calculated; sedative midazolam effect was estimated through an analogue percentage scale [12]. Fourteen days were left to clarify any remaining drug. In second phase, single oral 6-mg doses of midazolam into a $12 \mathrm{~g}$ white chocolate bar were administered to each subject, then blood sample collection, vital signs and sedation were recorded as described previously. The research protocol was approved by the Research Ethics Committee of this institution and an informed consent was obtained from each volunteer.

To quantify the midazolam plasma levels, the Juřica et al., method was slightly modified [13]. Pharmacokinetic parameters were calculated according to a non-compartmental model (Winnonlin ver 2.1 software, Pharsight Co.). Midazolam relative bioavailability was determined by comparing the area under the curve (AUC) of both formulations.

\section{Results}

\subsection{Midazolam Extraction}

Lipids have extensively been used to mask the bad aftertaste produced by a number of drugs, the bitterness of those such as gabapentin and acetaminophen is inhibited by mixing them with soy bean/glyceril monoesterate and stearyl stereate, respectively [14]. Another lipidic matrix, cocoa butter has been used as vehicle for suppository manufacturing [15], chewable tablets [16,17], and recently has been proposed as lubricant for coprocessing in tablets [18]. In the present work we assayed a midazolam oral formulation in white chocolate; this product contains at least $20 \%(\mathrm{w} / \mathrm{w})$ of cacao butter and $3.5 \%(\mathrm{w} / \mathrm{w})$ of milk fat, sugar (55\%) and flavours [9].

Due to the presence of cacao butter and milk fat in the oral formulation, the drug extraction process was com- plicated because the fat interferes with the HPLC quantification. For this reason, different solvents were tested: acetonitrile, diethyl ether, hexane, methanol, toluene and hexane/dichloromethane (70:30 v/v). Results about sample recovery and purity demonstrated that more hydrophobic solvents, ether, hexane and toluene, were as effective as the less hydrophobic ones (methanol and acetonitrile); however, methanol and acetonitrile yielded a cleaner sample (minimal amount of recovered fat). Taking account the cost-savings and commercial availability, methanol was selected as extraction solvent.

\subsection{Method Validation}

Retention times of midazolam and standard were 9.18 and 4.18 minutes, respectively (Figure 1, peaks 10 y 11). Calibration curves of midazolam were constructed with methanolic solutions and in chocolate matrix, in both conditions the peak areas versus midazolam concentrations were linear within the range of 5 to $60 \mu \mathrm{g} \cdot \mathrm{mL}^{-1}$; also, a good linear correlation was found, with $\mathrm{r}$ values of 0.9992 and 0.9991, respectively (Figure 2).

For both calibration curves, similar LOQ and LOD values were found; LOQ was found at $5 \mu \mathrm{g} \cdot \mathrm{mL}^{-1}$ and LOD at $500 \mathrm{ng} \cdot \mathrm{mL}^{-1}$. Absolute recovery of midazolam was $110.3 \%, 94.8 \%$ and $99.1 \%$ for the midazolam control concentrations, respectively. Results about the accuracy and deviation in the intra- and inter-day assays are depicted in Table 1; in both assays, the CV were lower than $5 \%$ and variations to the nominal value were lower than $\pm 3.5 \%$.

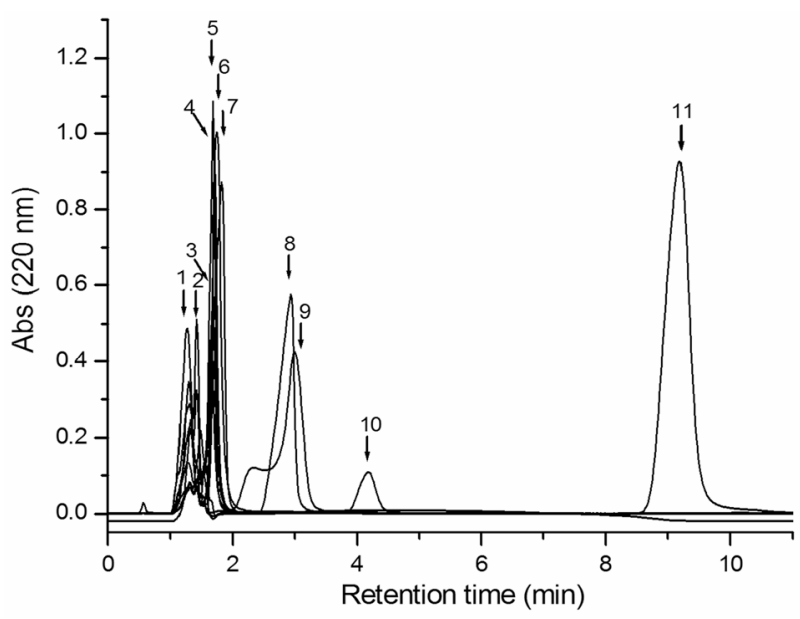

Figure 1. Selectivity chromatogram. Peaks retention times of: (1) ranitidine, $1.27 \mathrm{~min}$; (2) nimesulide, $1.42 \mathrm{~min}$; (3) captropril, $1.68 \mathrm{~min}$; (4) metronidazole, $1.70 \mathrm{~min}$; (5) acetaminophen, $1.68 \mathrm{~min}$; (6) trimethoprim, $1.73 \mathrm{~min}$; (7) acetylsalicylic acid, 1.82; (8) ketorolac, 2.93 ; (9) sulfamethoxazole 3.00 min; (10) external standard, 4.18 min; (11) midazolam, $9.18 \mathrm{~min}$. For all compounds $50 \mu \mathrm{L}$ were injected to the column. 


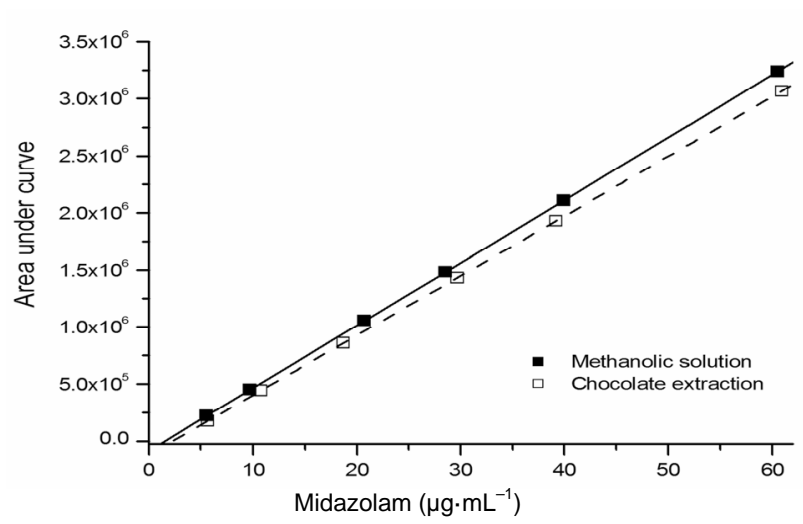

Figure 2. Linear regression analysis of the calibration curves. Midazolam dissolved in methanol ( $\square$ ) and midazolam extracted from chocolate ( $\square$ ).
Samples extracted with methanol and stored at $-20^{\circ} \mathrm{C}$ were stable for 48 hours, with variations to the nominal value of $\pm 7 \%$ and $\mathrm{CV} \leq 5 \%$; also, the compound remained stable after three freeze-thaw cycles with values of $14.97 \pm 0.46,24.30 \pm 1.17$ and $48.26 \pm 1.80 \mu \mathrm{g} \cdot \mathrm{mL}^{-1}$ for each control concentration, respectively.

Midazolam oral formulation stored at room temperature and exposed to light was stable for 14 days; after this time, a severe concentration reduction was observed in each control concentration (Table 2). Under refrigeration and darkness, drug remained without changes for up to 90 days, having deviations lower than $\pm 7 \%$ ( $>90 \%$ of initial concentration) and CV lower than $8 \%$ (Table 3). Similarly, the formulation stored at $40^{\circ} \mathrm{C}$ and in darkness was stable during a 90-day period (Table 4).

Table 1. Intra- and inter-day precision and accuracy of midazolam determination in chocolate matrix.

\begin{tabular}{ccccccc}
\hline & \multicolumn{3}{c}{ Analysis inter-day $(\mathrm{n}=5)$} & \multicolumn{3}{c}{ Analysis intra-day $(\mathrm{n}=9)$} \\
\hline $\begin{array}{c}\text { Concentration } \\
\text { added }(\mu \mathrm{g} / \mathrm{mL})\end{array}$ & $\begin{array}{c}\text { Concentration found } \\
\text { mean } \pm \mathrm{SD}(\mu \mathrm{g} / \mathrm{mL})\end{array}$ & $\mathrm{CV}(\%) \dagger$ & Deviation $(\%)^{*}$ & $\begin{array}{c}\text { Concentration found } \\
\text { mean } \pm \mathrm{SD}^{\circ}(\mu \mathrm{g} / \mathrm{mL})\end{array}$ & $\mathrm{CV}(\%) \dagger$ & Deviation $(\%) *$ \\
\hline 15 & $15.52 \pm 0.28$ & 1.8 & 3.5 & $14.83 \pm 0.67$ & 4.5 & -1.1 \\
25 & $24.78 \pm 1.14$ & 4.6 & -0.9 & $25.26 \pm 0.37$ & 1.5 & -1.0 \\
50 & $50.14 \pm 2.01$ & 4.0 & 0.3 & $48.78 \pm 2.32$ & 4.8 & -2.4 \\
\hline
\end{tabular}

${ }^{\circ}$ Calculated from linear regression equation; $\dagger \mathrm{CV}=($ Standard deviation $/$ mean $) \times 100 ; *$ Deviation $=($ Concentration found - concentration added $) /$ Concentration added $\times 100$.

Table 2. Stability of midazolam in chocolate matrix stored at room temperature and exposed to light.

\begin{tabular}{|c|c|c|c|c|}
\hline Concentration added $(\mu \mathrm{g} / \mathrm{mL})$ & Storage time & Concentration found mean $\pm \mathrm{SD}^{\circ}(\mu \mathrm{g} / \mathrm{mL})$ & $\mathrm{CV}(\%) \dagger$ & Deviation $(\%) *$ \\
\hline \multirow{7}{*}{15} & $0 \mathrm{~h}$ & $14.95 \pm 1.17$ & 7.8 & -0.3 \\
\hline & $6 \mathrm{~h}$ & $15.10 \pm 0.34$ & 2.2 & 0.7 \\
\hline & $24 \mathrm{~h}$ & $14.93 \pm 0.52$ & 3.5 & -0.5 \\
\hline & $7 \mathrm{~d}$ & $12.73 \pm 0.29$ & 2.3 & -15.1 \\
\hline & $14 \mathrm{~d}$ & $15.04 \pm 0.18$ & 1.2 & 0.3 \\
\hline & $30 \mathrm{~d}$ & $9.72 \pm 0.50$ & 5.1 & -35.2 \\
\hline & $60 \mathrm{~d}$ & $7.32 \pm 0.48$ & 6.6 & -51.2 \\
\hline \multirow{7}{*}{25} & $0 \mathrm{~h}$ & $25.27 \pm 1.17$ & 2.2 & 1.1 \\
\hline & $6 \mathrm{~h}$ & $24.42 \pm 0.53$ & 2.2 & -2.3 \\
\hline & $24 \mathrm{~h}$ & $23.67 \pm 0.56$ & 2.4 & -5.3 \\
\hline & $7 \mathrm{~d}$ & $21.86 \pm 0.29$ & 1.3 & -12.6 \\
\hline & $14 \mathrm{~d}$ & $24.34 \pm 0.39$ & 1.6 & -2.6 \\
\hline & $30 \mathrm{~d}$ & $17.83 \pm 1.06$ & 5.9 & -28.7 \\
\hline & $60 \mathrm{~d}$ & $14.06 \pm 1.56$ & 11.1 & -43.8 \\
\hline \multirow{7}{*}{50} & $0 \mathrm{~h}$ & $49.87 \pm 0.22$ & 0.4 & -0.3 \\
\hline & $6 \mathrm{~h}$ & $47.65 \pm 2.18$ & 4.6 & -4.7 \\
\hline & $24 \mathrm{~h}$ & $50.04 \pm 0.89$ & 1.8 & 0.1 \\
\hline & $7 \mathrm{~d}$ & $49.86 \pm 2.69$ & 5.4 & -0.3 \\
\hline & $14 \mathrm{~d}$ & $48.46 \pm 4.06$ & 8.4 & -3.1 \\
\hline & $30 \mathrm{~d}$ & $34.46 \pm 2.43$ & 7.0 & -31.1 \\
\hline & $60 \mathrm{~d}$ & $29.50 \pm 1.56$ & 5.3 & -41.0 \\
\hline
\end{tabular}

${ }^{\circ}$ Calculated from linear regression equation, $\uparrow \mathrm{CV}=($ Standard deviation $/$ mean $) \times 100 ; *$ Deviation $=($ Concentration found - concentration added $) /$ Concentration added $\times 100$ Storage time, $(\mathrm{h})$ hours, $(\mathrm{d})$ days. 
Table 3. Stability of midazolam in chocolate matrix stored under refrigeration $\left(4^{\circ} \mathrm{C}\right)$ and in darkness.

\begin{tabular}{|c|c|c|c|c|}
\hline Concentration added $(\mu \mathrm{g} / \mathrm{mL})$ & Storage time & Concentration found mean $\pm \mathrm{SD}^{\circ}(\mu \mathrm{g} / \mathrm{mL})$ & $\mathrm{CV}(\%) \dagger$ & Deviation $(\%)^{*}$ \\
\hline \multirow{7}{*}{15} & $0 \mathrm{~h}$ & $14.95 \pm 1.17$ & 7.8 & -0.3 \\
\hline & $3 \mathrm{~d}$ & $14.31 \pm 0.41$ & 2.9 & -4.6 \\
\hline & $7 \mathrm{~d}$ & $15.51 \pm 0.59$ & 3.8 & 3.4 \\
\hline & $14 \mathrm{~d}$ & $15.20 \pm 0.21$ & 1.4 & 1.3 \\
\hline & $30 \mathrm{~d}$ & $14.71 \pm 0.12$ & 0.8 & -1.9 \\
\hline & $60 \mathrm{~d}$ & $14.03 \pm 1.06$ & 7.6 & -6.5 \\
\hline & $90 \mathrm{~d}$ & $15.09 \pm 0.72$ & 4.8 & 0.6 \\
\hline \multirow{7}{*}{25} & $0 \mathrm{~h}$ & $25.27 \pm 1.17$ & 2.2 & 1.1 \\
\hline & $3 \mathrm{~d}$ & $24.53 \pm 0.39$ & 1.6 & -1.9 \\
\hline & $7 \mathrm{~d}$ & $23.62 \pm 1.32$ & 5.6 & -5.5 \\
\hline & $14 \mathrm{~d}$ & $25.21 \pm 1.71$ & 6.8 & 0.8 \\
\hline & $30 \mathrm{~d}$ & $23.57 \pm 1.82$ & 7.7 & -5.7 \\
\hline & $60 \mathrm{~d}$ & $24.45 \pm 0.97$ & 4.0 & -2.2 \\
\hline & $90 \mathrm{~d}$ & $24.49 \pm 0.93$ & 3.8 & -2.0 \\
\hline \multirow{7}{*}{50} & $0 \mathrm{~h}$ & $49.87 \pm 0.22$ & 0.4 & -0.3 \\
\hline & $3 d$ & $47.85 \pm 0.90$ & 1.9 & -4.3 \\
\hline & $7 \mathrm{~d}$ & $48.71 \pm 2.44$ & 5.0 & -2.6 \\
\hline & $14 \mathrm{~d}$ & $47.48 \pm 2.75$ & 5.8 & -5.0 \\
\hline & $30 \mathrm{~d}$ & $48.49 \pm 3.33$ & 6.9 & -3.0 \\
\hline & $60 \mathrm{~d}$ & $49.54 \pm 2.22$ & 4.5 & -0.9 \\
\hline & $90 \mathrm{~d}$ & $46.89 \pm 2.09$ & 4,5 & -6.2 \\
\hline
\end{tabular}

${ }^{\circ}$ Calculated from linear regression equation; $\dagger \mathrm{CV}=($ Standard deviation $/$ mean $) \times 100 ; *$ Deviation $=($ Concentration found - concentration added $) /$ Concentration added $\times 100$; Storage time, (h) hours, (d) days.

Table 4. Stability of midazolam in chocolate matrix stored at $40^{\circ} \mathrm{C}$ and in darkness.

\begin{tabular}{|c|c|c|c|c|}
\hline Concentration added $(\mu \mathrm{g} / \mathrm{mL})$ & Storage time & Concentration found mean $\pm \mathrm{SD}^{\circ}(\mu \mathrm{g} / \mathrm{mL})$ & $\mathrm{CV}(\%) \dagger$ & Deviation $(\%)^{*}$ \\
\hline \multirow{7}{*}{15} & $0 \mathrm{~h}$ & $14.95 \pm 1.17$ & 7.8 & -0.3 \\
\hline & $3 \mathrm{~d}$ & $13.10 \pm 0.10$ & 0.8 & -12.7 \\
\hline & $7 \mathrm{~d}$ & $12.59 \pm 0.96$ & 7.7 & -16.0 \\
\hline & $14 \mathrm{~d}$ & $13.66 \pm 1.40$ & 10.2 & -8.9 \\
\hline & $30 \mathrm{~d}$ & $12.94 \pm 1.66$ & 12.8 & -13.7 \\
\hline & $60 \mathrm{~d}$ & $12.62 \pm 0.30$ & 2.5 & -15.9 \\
\hline & $90 \mathrm{~d}$ & $13.76 \pm 0.93$ & 6.8 & -8.3 \\
\hline \multirow{7}{*}{25} & $0 \mathrm{~h}$ & $25.27 \pm 1.17$ & 2.2 & 1.1 \\
\hline & $3 \mathrm{~d}$ & $21.78 \pm 1.37$ & 6.3 & -12.9 \\
\hline & $7 \mathrm{~d}$ & $23.87 \pm 0.68$ & 2.9 & -4.5 \\
\hline & $14 \mathrm{~d}$ & $23.91 \pm 1.69$ & 7.1 & -4.4 \\
\hline & $30 \mathrm{~d}$ & $24.44 \pm 0.16$ & 0.7 & -2.2 \\
\hline & $60 \mathrm{~d}$ & $22.93 \pm 1.82$ & 7.9 & -8.3 \\
\hline & $90 \mathrm{~d}$ & $22.03 \pm 0.79$ & 3.6 & -11.9 \\
\hline \multirow{7}{*}{50} & $0 \mathrm{~h}$ & $49.87 \pm 0.22$ & 0.4 & -0.3 \\
\hline & $3 d$ & $48.61 \pm 2.30$ & 4.7 & -2.8 \\
\hline & $7 \mathrm{~d}$ & $51.67 \pm 1.07$ & 2.1 & 3.3 \\
\hline & $14 \mathrm{~d}$ & $50.26 \pm 0.68$ & 1.4 & 0.5 \\
\hline & $30 \mathrm{~d}$ & $46.42 \pm 1.89$ & 4.1 & -7.2 \\
\hline & $60 \mathrm{~d}$ & $47.10 \pm 1.98$ & 4.2 & -5.8 \\
\hline & $90 \mathrm{~d}$ & $45.51 \pm 2.61$ & 5.7 & -9.0 \\
\hline
\end{tabular}

${ }^{\circ}$ Calculated from linear regression equation; $\uparrow \mathrm{CV}=($ Standard deviation $/$ mean $) \times 100 ; *$ Deviation $=($ Concentration found - concentration added $) /$ Concentration added $\times 100$; Storage time, $(\mathrm{h})$ hours, $(\mathrm{d})$ days. 
None of the tested drugs in the method selectivity interfered with the peaks of midazolam or external standard (Figure 1).

\subsection{Relative Bioavailability Assay}

Pharmacokinetic parameters of both formulations were estimated from volunteers' plasma profiles using the Winnonlin software (Table 5). Although this preliminary assay included only two subjects, no appreciable differences in area under the curve (AUC) and peak plasma concentration $(\mathrm{Cmax})$ were found between them (Figure 3).

No differences in the onset of peak plasma concentration (Tmax), volume of distribution (Vd) and clearance $\left(C_{L}\right)$, were observed in both formulations. Relative bioavailability, obtained from the ratio between the AUC's of chocolate and apple juice, was $92.17 \%$, which suggests that both formulations share the same bioavailability; this leads to carry out a bioavailability assay with an adequate number of subjects to validate the bioequivalence of the white chocolate formulation.

\subsection{Physiological Variables Assessment}

Mean arterial pressure (MAP) values obtained at the beginning of the assay were different between both subjects ( 96.3 and $83.0 \mathrm{~mm} \mathrm{Hg}$, respectively), however, these values fluctuated uniformly throughout the study, regardless of subject or type of formulation (data not shown). MAP decreased about $20 \mathrm{~mm} \mathrm{Hg}$ within the first 30 to 60 minutes, which corresponds to the onset of the sedative effect, and then it rose to roughly the starting value obtained before the drug was administered.

Similar heart rate profiles were observed with both formulations, these values rose at the interval between 30 and 60 minutes, at 2 hours after drug administration the HR reached the minimal recorded values, and at 6 hours the HR returned to the initial values (data not shown).

The onset of the sedative effect in subject 2 was observed at $30 \mathrm{~min}$ after taking the drug orally, whereas subject 1 showed the onset 30 minutes later. However, the maximum sedative effect lasted 30 minutes, regardless of subject or formulation (data not shown).

\section{Discussion}

We developed a new oral formulation which was stable under the conditions assayed for up to 90 days; however, it is not stable at room temperature and exposed to light (clear wrap), which allows us to propose a light-protecting wrap for this new formulation and storage at $4^{\circ} \mathrm{C}$.

The preliminary bioavailability assay showed pharmacokinetic parameters compared to those reported by other authors $[19,20]$, and although we understand that is necessary to carry out a further study including a greater
Table 5. Pharmacokinetic parameters obtained from two healthy volunteers after taking two oral formulations of midazolam orally.

\begin{tabular}{ccc}
\hline $\begin{array}{c}\text { Pharmacokinetic } \\
\text { parameters }\end{array}$ & $\begin{array}{c}\text { Juice formulation } \\
\text { Mean } \pm \mathrm{SD}\end{array}$ & $\begin{array}{c}\text { Chocolate formulation } \\
\text { Mean } \pm \mathrm{SD}\end{array}$ \\
\hline Tmax $(\mathrm{h})$ & $0.75 \pm 0.35$ & $0.75 \pm 0.35$ \\
$\mathrm{Cmax}\left(\mathrm{ng} \cdot \mathrm{mL}^{-1}\right)$ & $59.0 \pm 24.60$ & $49.33 \pm 13.60$ \\
$\mathrm{~T}_{1 / 2}(\mathrm{~h})$ & $2.63 \pm 0.28$ & $1.71 \pm 0.01$ \\
$\mathrm{AUC}\left(\mathrm{ng} \cdot \mathrm{mL}^{-1} \cdot \mathrm{h}^{-1}\right)$ & $135.59 \pm 9.52$ & $124.98 \pm 18.37$ \\
$\mathrm{Vd}\left(\mathrm{L} \cdot \mathrm{Kg}^{-1}\right)$ & $1.97 \pm 0.06$ & $1.61 \pm 0.22$ \\
$\mathrm{C}_{\mathrm{L}}\left(\mathrm{L} \cdot \mathrm{Kg}^{-1}\right)$ & $0.52 \pm 0.04$ & $0.66 \pm 0.09$ \\
$\mathrm{~F}(\%)$ & & 92.17 \\
\hline
\end{tabular}

All the parameters were computed using the Winnonlin ver 2.1 software with a non-compartmental model; $\mathrm{F}=$ Apparent bioavailability obtained from (AUC chocolate/AUC juice)*100.

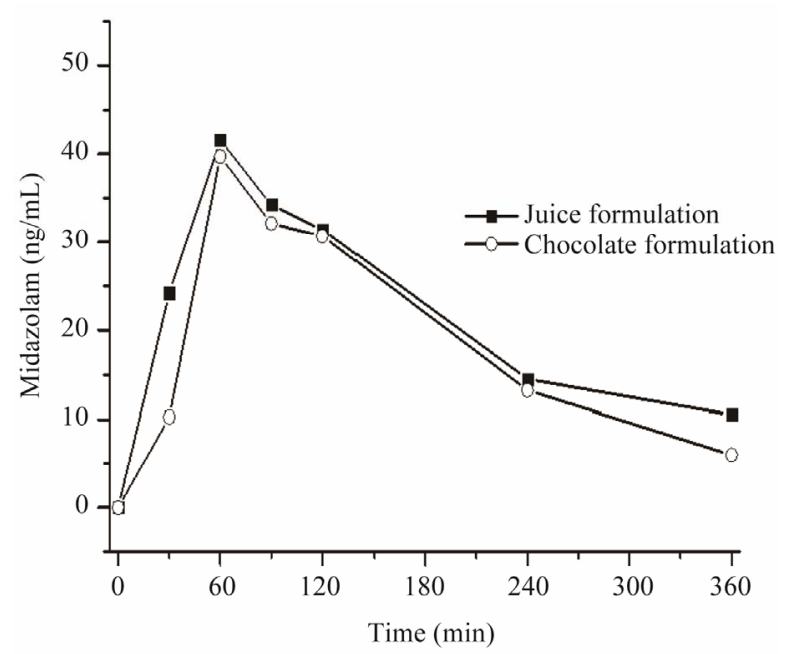

(a)

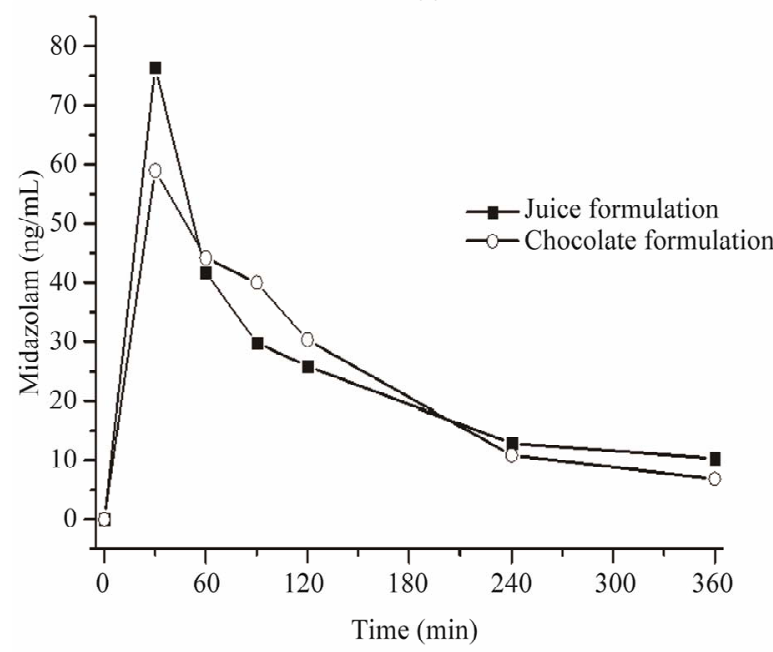

(b)

Figure 3. Pharmacokinetic profile of orally administered midazolam in apple juice (a) and in chocolate bar (०). (a) Subject 1, midazolam plasma profile and (b) Subject 2, midazolam plasma profile. 
amount of subjects, our results increased our interest in developing an alternative oral pediatric formulation, since its preliminary bioavailability is nearly the same to that of the apple juice formulation (AUC variation about of $8 \%$ ). Also we consider including a double blind study and a placebo group for both formulations for the performance of the final bioavailability study in healthy volunteers.

Cmax, Tmax and AUC values were similar to those reported by Schwagmaeier et al. [21], who studied midazolam pharmacokinetics in healthy volunteers, taking it also orally and under experimental conditions similar to ours. However, although our pharmacokinetic results are not different from others, it is only a preliminary study to evaluate the clinical performance of our HPLC method and a small approach about the bioavailability of the chocolate formulation.

Our results suggest that the midazolam formulation in white chocolate reaches the same plasma levels and induces physiological effects as the midazolam formulation in apple juice, but it improves the taste by diminishing the unpleasing flavour and having a more attractive presentation to the pediatric patient, easing its administration by professional health carers.

\section{REFERENCES}

[1] M. C. Nahata, "Lack of Pediatric Drug Formulations," Pediatrics, Vol. 104, 1999, pp. 607-609.

[2] M. C. Nahata and L. V. Allen Jr., "Extemporaneous Drug Formulations," Clinical Therapeutics, Vol. 30, No. 11, 2008, pp. 2112-2119. doi:10.1016/j.clinthera.2008.11.020

[3] C. Flores-Pérez, J. Flores-Pérez, H. Juárez-Olguín and M. Barranco-Garduño, "Frequency of Drug Consumption and Lack of Pediatric Formulations," Acta Pediatrica de México, Vol. 29, 2008, pp. 16-20.

[4] J. L. Blumer, "Clinical Pharmacology of Midazolam in Infants and Children," Clinical Pharmacokinetics, Vol. 35, No. 1, 1998, pp. 37-47. doi:10.2165/00003088-199835010-00003

[5] S. L. Steedman, J. R. Koonce, J. E. Wynn and N. H. Brahen, "Stability of Midazolam Hydrochloride in a Flavored Dye Free Oral Solution," American Journal of Hospital Pharmacy, Vol. 49, 1992, pp. 615-618.

[6] S. E. Walker, H. A. Grad, D. A. Haas and A. Mayer, "Stability of Parenteral Midazolam in an Oral Formulation," Anesthesia Progress, Vol. 44, 1997, pp. 17-22.

[7] V. Bhatt-Mehta, C. E. Johnson, L. Kostoff and D. Rosen, "Stability of Midazolam Hydrochloride in Extemporaneously Prepared Flavored Gelatin," American Journal of Hospital Pharmacy, Vol. 50, 1993, pp. 472-475.

[8] C. O. McMillan, I. A. Spahr-Schopfer, N. Sikich, E. Hartley and J. Lerman, "Premedication of Children with Oral Midazolam," Canadian Journal of Anaesthesia, Vol. 39, No. 6, 1992, pp. 545-550. doi:10.1007/BF03008315
[9] Federal Register-67 FR 62171, White Chocolate, Establishment of a Standard of Identity, 2002.

http://www.fda.gov/Food/LabelingNutrition/FoodLabelin gGuidanceRegulatoryInformation/RegulationsFederalRegisterDocuments/ucm189430.htm

[10] Norma Oficial Mexicana NOM-073-SSA1-2005, Diario Oficial de la Federación, 2006.

[11] NORMA Oficial Mexicana NOM-177-SSA1-1998, Diario Oficial de la Federación, 1999.

[12] H. A. Argente and M. E. Álvarez, "Semiología Médica. Fisiopatología, Semiotecnia y Propedéutica. Enseñanza Basada en el Paciente," Panamericana, México, 2005.

[13] J. Jurica, M. Dostálek, J. Konecný, Z. Glatz, E. Hadasová and J. Tomandl, "HPLC Determination of Midazolam and Its Three Hydroxy Metabolites in Perfusion Medium and Plasma from Rats," Journal of Chromatography B: Analytical Technologies in the Biomedical and Life Sciences, Vol. 852, No. 1-2, 2007, pp. 571-577. doi:10.1016/j.jchromb.2007.02.034

[14] H. Sohi, Y. Sultana and Y. Khar, "Taste Masking Technologies in Oral Pharmaceuticals: Recent Developments and Approaches," Drug Development and Industrial Pharmacy, Vol. 30, 2004, pp. 429-448. doi:10.1081/DDC-120037477

[15] S. A. Ibrahim, T. H. El-Faham, S. S. Tous and E. M. Mostafa, "Formulation, Release Characteristics and Evaluation of Ibuprofen Suppositories," International Journal of Pharmaceutics, Vol. 61, No. 1-2, 1990, pp. 1-7. doi:10.1016/0378-5173(90)90037-5

[16] H. Suzuki, H. Onishi, Y. Takahashi, M. Iwata and Y. Machida, "Development of Oral Acetaminophen Chewable Tablets with Inhibited Bitter Taste," International Journal of Pharmaceutics, Vol. 251, No. 1-2, 2003, pp. 123-132. doi:10.1016/S0378-5173(02)00595-1

[17] E. H. Kim and H. K. Choi, "Preparation of Various Solid-Lipid Beads for Drug Delivery of Enrofloxacin," Drug Delivery, Vol. 11, 2004, pp. 365-370. doi:10.1080/10717540490265414

[18] A. A. Adeagboo and G. Alebiowu, "Evaluation of Cocoa Butter as Potential Lubricant for Coprocessing in Pharmaceutical Tablets," Pharmaceutical Development and Technology, Vol. 13, 2008, pp. 197-204. doi:10.1080/10837450801949400

[19] M. D. Reed, A. Rodarte, J. L. Blumer, K. C. Khoo, B. Akbari and S. Pou, "The Single-Dose Pharmacokinetics of Midazolam and Its Primary Metabolite in Pediatric Patients after Oral and Intravenous Administration," Clinical Pharmacolology, Vol. 41, 2001, pp. 1359-1369.

[20] J. Martens-Lobenhoffer, S. Eisenhardt, U. Tröger, W. Röse and F. P. Meyer "The Effect of Anxiety and Personality on the Pharmacokinetics of Oral Midazolam," Anesthesia and Analgesia, Vol. 92, No. 3, 2001, pp. 621-624. doi:10.1213/00000539-200103000-00012

[21] R. Schwagmeier, S. Alincic and H. W. Striebel, "Midazolam Pharmacokinetics Following Intravenous and Buccal Administration," Britain Journal of Clinical Pharmacology, Vol. 46, No. 3, 1998, pp. 203-206. doi:10.1046/j.1365-2125.1998.00781.x 